\title{
Üçüncü Basamak Bir Hastaneye Başvuran Riskli Popülasyonda Oral Glukoz Tolerans Testi ile Diabetes Mellitus ve Prediyabet Prevalansının Tespiti
}

\author{
Safiye ÇATALÇAM ${ }^{1}$, Ebru BOZ UZALDI ${ }^{1}$, Dilek KARAKAYA ARPACI ${ }^{1}$, Taner BAYRAKTAROĞLU ${ }^{1}$, \\ Muammer BİLICí2
}

${ }^{1}$ Bülent Ecevit Üniversitesi Tip Fakültesi, Endokrinoloji ve Metabolizma Hastalıkları Bilim Dalı, Zonguldak

${ }^{2}$ Bülent Ecevit Üniversitesi Tıp Fakültesi, İç Hastalıkları Anabilim Dalı, Zonguldak

\begin{abstract}
ÖZET
Amaç: Diabetes mellitus, sıklığı ve yarattığı sorunlar nedeniyle tüm dünyada önemi gittikçe artan toplumsal bir sağlık sorunudur. Burada bilinen diyabet hikayesi olmayan ve Oral Glukoz Tolerans Testi (OGTT) yapılacak risk faktörlü bireylerde prediyabet ve diabetes mellitus prevalansının araştırılmasını amaçladık.

Gereç ve Yöntemler: Üçüncü basamak bir hastaneye başvuran ve diabetes mellitus açısından risk faktörü bulunduran bireylere OGTT yapılarak diyabetik ve prediyabetik (bozulmuş açlık glisemisi, bozulmuş glukoz toleransı) olguların oranı belirlendi. Olguların yaş, cinsiyet, açlık kan glukozu, OGTT 2.saat kan glukozu ve glikozile hemoglobin (A1C) değerleri belirlenerek cinsiyete göre farklılıklar araştırıldı. Glisemik tablo alt gruplarına göre karşılaştırmalar yapıldı.

Bulgular: Oral glukoz tolerans testi ile risk faktörü bulunduran 187 olguda (\%36,5) glukoz toleransı normal bulundu. Yeni diyabet tanısı 48 (\% 9.4) olguda saptandı. Ayrıca 150 olguda (\%29,3) Bozulmuş Açlık Glukozu (BAG), 48’inde (\%9.4) Bozulmuş Glukoz Toleransı (BGT) ve 79'unda (\%15.4) BAG ve BGT birlikteliği tespit edildi. Erkeklerin yaş, açlık kan glukozu, OGTT 2. saat glukozu ve A1C ortalamaları ile diabetes mellitus oranı kadınlara göre anlamlı olarak yüksekti $(\mathrm{p}<0.05)$. Diyabetik ve prediyabetiklerin yaş ortalamaları, açlık kan glukozu, OGTT 2. saat kan glukozu ile A1C ortalamaları anlamlı olarak yüksekti ( $<<0.05)$. Bu arada normal glukoz toleranslı ve prediyabetikler içerisinde kadın cinsiyet oranı belirgin yüksek iken diyabetiklerde erkek cinsiyet oranı daha yüksek bulundu.

Sonuç: Diabetes mellitus ve prediyabet tanısı için OGTT tek başına önerilen bir testtir. Diyabet için risk faktörü pediyabet prevalansı toplumda yüksek ve cinsiyete göre farklılıklar göstermektedir. Oral glukoz tolerans testi yapılmış riskli gruplarda diabetes mellitus tanı prevalansımız toplumumuza ait bildirilenlere benzer oranda görünmektedir.
\end{abstract}

Anahtar Sözcükler: Oral glukoz tolerans testi, Prediyabet, Diabetes mellitus

\section{The Prevelance of Diabetes Mellitus and Prediabetes by Oral Glucose Tolerance Test in Risk Population Applying to a Tertiary Hospital}

\begin{abstract}
Aim: Diabetes mellitus is an increasingly public health problem all over the world, due to the frequency and problems it creates. We aimed to investigate the prevalence of prediabetes and diabetes mellitus in individuals with no known history of diabetes and risk factors for Oral Glucose Tolerance Test (OGTT).

Material and Methods: The proportion of diabetic and prediabetic (impaired fasting glycemia, impaired glucose tolerance) cases was determined by performing OGTT on those who applied to a tertiary care hospital and had a risk factor for diabetes mellitus. The age, sex, fasting blood glucose, OGTT 2nd hour blood glucose and glycosylated hemoglobin (A1C) values of the cases were determined and differences according to sex were investigated. Comparisons were made according to glycemic subgroups.
\end{abstract}

DOI: $10.25048 /$ tjdo.2017.18 
Results: Glucose tolerance was normal in 187 cases (36.5\%) with risk factor by oral glucose tolerance test. New diabetes was diagnosed in 48 (9.4\%) cases. Together Impaired Fasting Glycemia (IFG) and Impaired Glucose Tolerance (IGT) were detected in 79 cases (15.4\%). IFG in 150 cases (29.3\%), and IGT 48 cases (9.4\%). Men's age, fasting blood glucose, OGTT 2nd hour glucose and A1C averages and diabetes mellitus ratio were significantly higher than women $(\mathrm{p}<0.05)$. Mean averages of diabetic and prediabetic patients, fasting blood glucose, OGTT 2nd hour blood glucose and A1C averages were significantly higher than normal group $(<0.05)$. Meanwhile, the female sex ratio was significantly higher in normal glucose tolerant and prediabetics, while the male sex ratio was higher in diabetics.

Conclusion: OGTT is a stand-alone test for the diagnosis of diabetes mellitus and prediabetes. The prevalence of prediabetes, a risk factor for diabetes, can be detected at high levels in society and varies according to sex.

Key Words: Oral glucose tolerance test, Prediabetes, Diabetes mellitus

\section{GIiRIŞ}

Diabetes mellitus, pankreastan insülin sekresyonunun mutlak veya rölatif yetersizliği veya insülin etkisizliği ya da insülin melokülündeki yapısal bozukluklar sonucu gelişen, hiperglisemi ve glukoz yüksekliği ile karakterize; karbonhidrat, protein ve lipit metabolizmalarının bozukluğu ile seyreden, akut metabolik ve kronik dejeneratif komplikasyonlara neden olan bir sendromdur (1). Günümüzde diyabet, sıklığı ve yarattığı sorunlar nedeniyle tüm dünyada önemi gittikçe artan bir sağllk sorunudur $(2,3)$ Uluslararası Diyabet Federasyonu ("International Diabetes Federation", IDF) tarafindan 2013 yılında yayınlanan 'Altıncı Diyabet Atlası' dünyada mevcut durumu ve geleceği ile ilgili önemli verileri içermektedir (4). Dünyadaki diyabetli birey sayısı 2013 itibari ile 382 milyon iken bu sayının 2035 yılında 592 milyona ulaşacağı öngörülmektedir Diyabet prevalansı Asya ülkelerinde Batı ülkelerine oranla daha hızlı artış göstermektedir (4).

Altıncı Diyabet Atlası tahminlerine göre Türkiye, diyabetli nüfus itibari ile diyabetin dünyada en yüksek olacağı ilk 10 ülke arasına girmektedir (4). Tüm dünyada olduğu gibi ülkemizde de diyabet prevalansı iki katına çıkarak arttığı ve \%13.7 olduğu görülmüştür $(5,6)$. Prevalansın bu kadar hızlı artışı sağlık problemleri ve bununla ilişkili olarak ekonomik problemler doğurmaktadır. Türkiye'de TURDEP-II çalışması verilerine göre diyabetli bireylerin $\% 45,5$ oranı hastalığın varlı̆̆ından haberdar değildir (6). Diyabet prevalansını azaltmak için önleyici programlar arasındaki ilk adım riskli insanları bulmaktır. Bozulmuş Açlık Glukozu (BAG), Bozulmuş Glukoz Toleransı (BGT) veya bunların birlikteliği (BAG+BGT) önemli diyabete yatkınlık durumudur ve 'prediyabet' olarak adlandırılmaktadır (1). Bu riskli grubu saptamak için açlık plazma glukozu, Oral Glukoz Tolerans Testi (OGTT) 2. saat glukozu ya da glikozillenmiş hemoglobin A1c (A1C) kullanılmaktadır (1).

Burada bilinen diyabet anamnezi olmayan ve OGTT yapılmış risk faktörü bulunan kişilerde prediyabet ve diabetes mellitus prevalansının araştırılmasını ve analizini amaçladık.

\section{GEREÇ ve YÖNTEMLER}

\section{Çalışma Grubu}

Çalışmada Ocak 2015- Aralık 2016 tarihleri arasında Bülent Ecevit Üniversitesi Sağlık Uygulama ve Araştırma Merkezi Endokrinoloji ve Metabolizma Hastalıkları Polikliniğine başvuran ve OGTT yapılan $\geq 18$ yaş üzeri olguların taranmasını amaçladık. Olguların yaş, cinsiyet, açlık kan glukozu, OGTT 2.saat kan glukozu ve glikozile hemoglobin (HbAlc, A1C) değerleri tespit edildi.

Çalışmaya diyabet açısından riskli kabul edilen yaşı $\geq 45$ yll, vücut kütle indeksi (VKİ) $\geq 25 \mathrm{~kg} / \mathrm{m} 2$ üzeri, birinci derece akrabalarda diyabet tanısı, hipertansiyonu $(\geq 140 / 90$ $\mathrm{mmHg}$ ), dislipidemi (HDL-kolesterol $\leq 35 \mathrm{mg} / \mathrm{dl}$ veya trigliserid $\geq 250 \mathrm{mg} / \mathrm{dl}$ ) olanlar, iri bebek doğumu veya gestasyonel diyabet hikayeli kadınlar, daha önce BAG veya BGT saptananlar, polikistik over sendromlu (PKOS) kadınlar, koroner, periferik veya serebral vasküler hastalığı bulunanlar, sedanter yaşam süren veya fizik aktivitesi düşük, sözlü ve yazılı bilgilendirilmiş olur veren bireyler alındı (1,7). Mevcut diyabet varlığı, gebelik ve emzirme dönemindeki kadınlar, karaciğer ve böbrek yetersizliği, Cushing sendromu, Akromegali, feokromositoma ve tiroid fonksiyon bozukluğu bulunanlar çalışma dışı bırakıldı. Araştırma için Bülent Ecevit Üniversitesi Klinik Araştırmalar Etik Kurulu onayı alındı.

Açlık kan glukozu için en az sekiz saatlik açlık sonrası venöz kan örnekleri alınmıştır. Devamında 75 gr glukoz $250 \mathrm{ml}$ su ile içirilerek ikinci saat venöz kan örnekleri temin edilmiştir. Açlık kan glukozu 100-125 mg/dl ve OGTT 2. saat kan glukozu $\leq 140 \mathrm{mg} / \mathrm{dl}$ saptananlar BAG, açlık kan glukozu $<100$ mg/dl ve OGTT 2. saat kan glukozu 140-199 mg/dl olanlar BGT ve hem açlık kan glukozu 100-125 mg/ dl hem de OGTT 2. saat kan glukozu 140-199 mg/dl olanlar ise BAG+BGT olarak tanımlanmıştır. Açlık kan glukozu $\geq$ $126 \mathrm{mg} / \mathrm{dl}$ ve OGTT 2. saat kan glukozu $\geq 200 \mathrm{mg} / \mathrm{dl}$ olanlar aşikar Diabetes mellitus kabul edilmiştir $(1,7)$. 


\section{İstatistiksel Analiz}

Verilerin istatistiksel analizi SPSS 19 (Statistical Pakage For Social Science) ile değerlendirildi. Tanımlayıcı istatistiksel sürekli değişkenler için ortalama \pm standart sapma ve nomimal değişkenler ise yüzde (\%) olarak gösterildi. Oral glukoz tolerans testi sonuçlarına göre normal, prediyabet ve diyabet grupları belirlenerek cinsiyet ve gruplar arası yaş, açlık kan glukozu, OGTT 2. saat glukozu ve A1C ortalamaları karşılaştırıldı. Tanımlayıcı verilerin analizinde student- $t$ testi, nominal değişkenlerin karşılaştırmasında $x^{2}$ testi kullanıld. Hesaplamalarda saptanan $\mathrm{p}<0.05$ değerleri istatistiksel olarak anlamlı kabul edildi.

\section{BULGULAR}

Ocak 2015- Aralık 2016 arası Bülent Ecevit Üniversitesi Sağlık Uygulama ve Araştırma Merkezi Endokrinoloji ve Metabolizma Hastalıkları polikliniğine başvuran 18 yaş ve üzeri riskli 512 olgu değerlendirmeye alındı. Oral glukoz tolerans testi yaptığımız bu olguların yaş ortalaması 50,24 $\pm 13,95$ yll ve 345’i kadın $(\% 67,38)$ idi. Bütün gruba ait açlık kan glukozu ortalaması 102,36 $\pm 11,59 \mathrm{mg} / \mathrm{dl}$, OGTT 2. saat kan glukozu ortalaması $130.74 \pm 45.83$ ve A1C ortalama değeri \% $6.05 \pm 0.60$ saptand1.

Oral glukoz tolerans testi sonrası çalışma grubunun 187'sinde $(\% 36,5)$ glukoz toleransi normal bulundu. Yeni diyabet tanısı konulan olgu sayısı 48 (\% 9.4) olarak saptandı. Yeni saptanan prediyabet tanılı 277 (\%54.1) olgu bulunurken, 150 olguda $(\% 29,3)$ BAG, 48'inde (\%9.4) BGT ve 79'unda (\%15.4) BAG ve BGT birlikteliği tespit edildi.

Diyabet taraması yapılan erkeklerin yaş, açlık kan glukozu, OGTT 2. saat glukozu ve A1C ortalamaları ile diabetes mellitus oranı kadınlara göre anlamlı olarak yüksek bulundu $(\mathrm{p}<0.05)$ (Tablo 1).

Normal glukoz toleransı, prediyabet ve diyabeti olan hastaların demografik ve laboratuvar verilerinin karşılaştırılması ise Tablo 2'de verilmiştir. Diyabetik ve prediyabetiklerin yaş ortalamaları, açlık kan glukozu, OGTT 2. saat kan glukozu ile A1C ortalamaları anlamlı olarak yüksek tespit edilmiştir $(\mathrm{p}<0.05) . \mathrm{Bu}$ arada normal glukoz toleranslı ve prediyabetikler içerisinde kadın cinsiyet oranı belirgin yüksek iken diyabetiklerde erkek cinsiyet oranı daha yüksek bulundu (Tablo 2).

\section{TARTIȘMA}

Yaşam beklentisinin artması, ekonomik büyüme ve yaşam tarzındaki değişikler nedeniyle son zamanlarda Türkiye'de de diabetes mellitus önemli bir sağlik sorunu haline gelmiştir (3,7). Dünya Sağlık Örgütü ve Amerikan Diyabet Cemiyeti tarafindan diyabet tanısında altın standart olarak OGTT önerilmektedir $(8,9)$. OGTT testi için açlık gerekmektedir. Diyabet tanısı için açlık plazma glukozu $\geq 126 \mathrm{mg} / \mathrm{dl}$ veya OGTT ile 2 . saat kan glukozu $\geq 200 \mathrm{mg} /$ dl ya da A1C seviyesinin $\geq \% 6.5$ olması gereklidir. Yüksek performanslı likit kromatografisi ('High Performance

Tablo 1: OGTT yapılmış riskli gruba ait cinsiyete göre bulguların dağılımı

\begin{tabular}{lccc}
\hline Parametreler & Erkek $(\mathbf{n}=\mathbf{1 6 4})$ & Kadın $(\mathbf{n}=\mathbf{3 4 5})$ & $\mathbf{P}$ \\
\hline Yaş $($ Yıl \pm SD) & $52.52 \pm 13.79$ & $49.17 \pm 13.92$ & 0.011 \\
\hline Açlık kan glukozu $(\mathbf{m g} / \mathbf{d l} \pm$ SD) & $103.43 \pm 12.1$ & $101.86 \pm 11.30$ & 0.102 \\
\hline OGTT 2. Saat Kan glukozu (mg/dl \pm SD) & $138.45 \pm 55.28$ & $127.10 \pm 40.21$ & 0.146 \\
\hline A1C $(\% \pm$ SD) & $6.19 \pm 0.61$ & $5.97 \pm 0.58$ & $<0.01$ \\
\hline Normal glukoz toleransı [n(\%)] & $50(30.48)$ & $137(39.71)$ & \\
\hline Prediyabetik [n(\%)] & $86(52.43)$ & $191(55.36)$ & \\
\hline Diabetes mellitus [n(\%)] & $28(17.07)$ & $20(6.79)$ & $<0.01$ \\
\hline
\end{tabular}

Tablo 2: Diyabetik, prediyabetik ve normal glisemik olgulara ait bulguların dağılımı

\begin{tabular}{|c|c|c|c|c|}
\hline Bulgular & $\begin{array}{l}\text { Normal glukoz toleransi } \\
\quad(n=187, \% 36,52)\end{array}$ & $\begin{array}{c}\text { Prediyabetik } \\
(\mathrm{n}=277, \% 54,10)\end{array}$ & $\begin{array}{c}\text { Diabetes mellitus } \\
(\mathrm{n}=\mathbf{4 8 , \% 9 , 3 7 )}\end{array}$ & p değeri \\
\hline Yaş $(\mathrm{Y} 11 \pm S D)$ & $43.74 \pm 4.60$ & $53.34 \pm 12.10$ & $57.70 \pm 11.45$ & 0.029 \\
\hline Cinsiyet $(\mathrm{E} / \mathrm{K})$ & $50 / 137$ & $86 / 191$ & $28 / 20$ & $<0.01$ \\
\hline Açlık kan glukozu $(\mathrm{mg} / \mathrm{dl} \pm \mathrm{SD})$ & $91.87 \pm 7.50$ & $107.79 \pm 8.70$ & $111.95 \pm 9.16$ & $<0.01$ \\
\hline OGTT 2.saat kan glukozu $(\mathrm{mg} / \mathrm{dl} \pm \mathrm{SD})$ & $101.82 \pm 23.19$ & $132.79 \pm 33.14$ & $231.56 \pm 23.06$ & $<0.01$ \\
\hline $\mathrm{A} 1 \mathrm{C}(\% \pm \mathrm{SD})$ & $5.86 \pm 0.57$ & $6.11 \pm 0.60$ & $6.26 \pm 0.57$ & $<0.01$ \\
\hline
\end{tabular}


Liquid Cromotography', HPLC) ile ölçülmüş A1C diyabet tanısı için önerilmektedir (1). Özellikle A1C için açlık gerekmemektedir. Ancak A1C ölçümü pahalı bir yöntem olup her klinikte yapılamamaktadır. Glukoz bakılan her merkezde OGTT ise yapilabilmektedir ve kolayca diyabet tanısı konulmaktadır. Çalışmalar göstermiştir ki OGTT 'ye karşı A1C ile diyabet tanısı konulduğu zaman prevalans düşmektedir (10).

Ülkemizde 1997-1998 yılları arasında yapılan TURDEP-1 çalışmasında diyabet prevalansı $\% 7.2$ ve bozulmuş glukoz intoleransı prevalansı ise \%6.7 saptand $1(5,6)$. Ancak ilkinde olgulara OGTT yapılmamıştı (5). Oniki yıl sonra yapılan TURDEP-2 çalışmasında ise diyabet prevalansı TURDEP-1'e oranla \%90 artarak \%13.7’ye yükselmiştir (6). Çalışmamızda diyabet oranı \%9.4 olup TURDEP-2 verilerine oranla düşük saptandı. TURDEP-2 çalışmasında prediyabet prevalansı ise TURDEP-1'e oranla \%106 artarak \%30.8 oranında saptanırken çalışma grubumuzda ise prediyabet prevalansı \%. 54.1 olup Türkiye verilerinin üstünde idi. TURDEP-2 çalışmasında BAG \%14.7 iken çalışmamızda \% 29.3 yüksek, BGT ise TURDEP-2 de \%7.9 iken araștırmamızda \% 9.4 oranında benzer bulundu. TURDEP-2 çalışmasında diyabet kadınlarda daha fazla iken çalışmamızda ise erkeklerde daha fazla idi. Ayrıca çalışmamızda prediyabet kadınlarda fazla olarak saptandı. Farklı ülkelerin çalışmalarında ise erkeklerde daha fazla bulunmuştur (11-14). Bu araştırmada OGTT ile olgularda diyabet tanısı araştırılırken A1C tanı için kullanılmamıştır. Özellikle A1C eritrosit ömründen, membran geçirgenliğinden, hemoglobin içeriğinden ve etnik değişkenlikten değişmektedir $(15,16)$. Güney Afrika'da yapılan bir çalışmada diyabet prevalansı $\% 8.2$ ve prediyabet oranı ise $\% 19.8$ (\%5.1 BAG, \%86.6 BGT ve \%8.3 BAG+BGT) bildirilmiştir (17). Araştırmamızda prediyabet oranı OGTT yapılan olgularımızda bu araştırmada bildirilenden yüksekti.

Araştırmamızda erkeklerin yaş ortalaması TURDEP-2'ye benzer oranda daha fazla idi. TURDEP-2 de (6) kadınlarda açlık plazma glukozu, tokluk plazma glukozu ve A1C daha yüksek iken çalışmamızda cinsiyetler arasında açlık plazma glukozu, tokluk plazma glukozu açısından fark yoktu. Ancak A1C erkeklerde anlamlı olarak daha yüksek idi $(\mathrm{p}<0.05)$. Çin'de yapılan bir çalışmada diyabet prevalansı \%9.7 oranı ile çalışmamızda bulduğumuz orana benzerdir (18). Çalışmamızda yüksek riskli bireylerde OGTT ile tanı konulan diyabetlilerin oranının genel populasyondaki verilere göre düşüklüğünün bir diğer nedeni diyabet tanısı almış ve tedavisi planlanmış olguların araştırmaya katılmamış olmasıdır.

Ayrıca diyabet prevalansının yaş ile arttı̆̆ 1 bildirilmiştir (19). Bu çalışmada da benzer şekilde diyabetik olan hastalar prediyabet ve normal glukoz toleransi olan hastalara oranla daha yaşlilardı. Hem diyabet hem de prediyabet tanısı için tek başına OGTT önerilen bir testtir (20). Çalışmalar göstermiştir ki sadece açlık plazma glukozu ile sadece diyabetiklerin \%35'i saptanırken OGTT ile \%46-60 oranında saptanmaktadır $(18,21,22)$. Diyabetik hastaların karakteristik özellikleri ve risk faktörleri diyabet tanısının belirlenmesi için kullanılan yönteme göre değişmektedir. Çalıșmamızda olguların beden kütle indeksi, kan basıncı lipid değerlerine ait verileri tanımlanmamıștır ve risk faktörleri sınıflandırılmamıștır.

Diyabet, açlık plazma glukozu (BAG), oral glukoz tolerans testinde (OGTT) 2. saat plazma glukozu ve A1c de dahil olmak üzere farklı belirteçler temelinde tanımlanmıştır. Farklı diyagnostik tanımlamaların hem diyabet popülasyon prevalansı hem de daha önce teşhis edilmemiş bireylerin araştırmalarında farklılık gösterebilmektedir (16). Özellikle glukoz temelli testlere göre A1C kullanılırsa daha önce teşhis konulmamış kişilerin önemli bir bölümünü tanımlayamaz (16). Ulusal ve uluslararası epidemiyolojik verilere göre aşikar diyabet prevalansında giderek artış olmasına rağmen yüksek riskli gruplarda OGTT yapılması diyabet tanısı açısından altın standarttır. Bu teste göre çalışma grubumuz yüksek riskli olsa da diyabet tanısı ulusal epidemiyolojik veriler yakın ve uyumlu bir sonuç vermiştir. OGTT sonucuna göre prediyabet ya da BAG ve BGT'li bireylerin oranındaki yükseklik devam etmektedir.

Sonuç olarak diabetes mellitus tanısında her yerde yapılabilmesi nedeniyle OGTT halen altın standart olma özelliğini korumaktadır. Çalışmamızda OGTT yapılan riskli populasyondaki bireylerin glisemik tablosu tanımlanmıştır. Diyabet için risk faktörü olan prediyabetik durumun prevalansı yüksek olması, cinsiyete göre farklılıklar olsa da riskli gruplarda diabetes mellitus tanı prevalansı toplumumuza ait bildirilen prevalansa yakındır. Aşikar diyabetlilerin katılması ile bu oran daha da yüksek saptanacaktır. Epidemiyolojik açıdan OGTT gibi ucuz ve kolay yöntemlerle diabetes mellitusun tanınmasının ve riskli gruplarda taramanın yapılarak yeni diyabetiklerin tespiti önemlidir.

\section{KAYNAKLAR}

1. American Diabetes Association. 2.Classification and Diagnosis of Diabetes. Diabetes Care. 2017;40(Suppl 1):S11-S24.

2. American Diabetes Association. 1.Promoting Health and Reducing Disparities in Populations. Diabetes Care. 2017;40(Suppl 1):S6-S10.

3. World Health Organization. Diabetes Action Now. Switzerland,2004 (Accessed date 08.11.2017, http://www.who. int/diabetes/actionnow/booklet/en/)

4. İnternational Dabetes Federation. Diabetes Atlas. 6thedition, 2013. (Accessed date 08.11.2017, http://www.idf.org/ diabetesatlas). 
5. Satman I, Yilmaz T, Sengül A, Salman S, Salman F, Uygur S, Bastar I, Tütüncü Y, Sargin M, Dinççag N, Karsidag K, Kalaça S, Ozcan C, King H. Population-based study of diabetes and risk characteristics in Turkey: results of the turkish diabetes epidemiology study (TURDEP). Diabetes Care. 2002;25(9):1551-6.

6. Satman I,Ömer B,Tutuncu Y,Kalaca S,Gedik S,Dinccag N,Karsıdag K,Genc S,Telci A,Canbaz B,Turker F,Yılmaz T,Cakır B,Tuomiletho j;TURDEP -II Study Group.Twelveyear trends in the prevalance and risk factors of diabetets and prediabetes in Turkısh adults. Eur J Epidemiol. 2013;28(2):16980 .

7. Türkiye Endokrinoloji ve Metabolizma Derneği. Diabetes Mellitus ve Komplikasyonlarının Tanı,Tedavi ve İzlem Kılavuzu, Ankara, Miki Matbaacılık San. ve Tic. Ltd. Şti. 2017. (Erişim tarihi 08.11.2017 http://turkendokrin.org/files/ DIYABET2017_web.pdf).

8. World Healt Organization. Diabetes Mellitus: Report of a who Study Group Geneva. Teac Rep Ser No 727,1985. (Accessed Date 08.11.2017 http://apps.who.int/iris/ bitstream/10665/39592/1/WHO_TRS_727.pdf).

9. Expert Committee on the Diagnosis and Classification of Diabetes Mellitus. Report of the Expert Committee on the diagnosis and classification of diabetes mellitus. Diabetes Care 2003; 26:S5-S20.

10. Christensen DL, Witte DR, Kaduka L, et al. Moving to A1Cbased diagnosis of diabetes as a different impact on prevalence in different ethnic groups. Diabetes Care 2010; 33:580-582.

11. Kaiser A, Vollenweider P, Waeber G, Waeber G, MarquesVidal P. Prevalence, awareness and treatment of type 2 diabetes mellitus in Switzerland: the CoLaus study.Diabet Med. 2012;29(2):190-7.

12. Morimoto A Nushimura R Tajima N. trend in the epidemiology of patients w,th diabetes in Japan. Jpn Med Assoc J. 2010; 53:36-40.

13. Ylihärsilä $\mathrm{H}^{1}$, Lindström J, Eriksson JG, Jousilahti P, Valle TT, Sundvall J, Tuomilehto J. Prevalence of diabetes and impaired glucose regulation in 45- to 64-year-old individuals in three areas of Finland. Diabet Med. 2005;22(1):88-91.
14. Consequences of the new diagnostic criteria for diabetes in older men and women. DECODEStudy (Diabetes Epidemiology: Collaborative Analysis of Diagnostic Criteria in Europe) Diabetes Care. 1999;22(10):1667-71.

15. Selvin E, Steffes MW, Ballantyne CM, Hoogeveen RC, Coresh J, Brancati FL. Racial differences in glycemic markers: a crosssectional analysis of community-based data. Ann Intern Med. 2011;154(5):303-9.

16. NCD Risk Factor Collaboration (NCD-RisC). Effects of diabetes definition on global surveillance of diabetes prevalence and diagnosis: a pooled analysis of 96 populationbased studies with 331,288 participants. Lancet Diabetes Endocrinol. 2015;3(8):624-37.

17. Kengne AP, Erasmus RT, Levitt NS, Matsha TE. Alternative indices of glucose homeostasis as biochemical diagnostic tests for abnormal glucose tolerance in an African setting. Prim Care Diabetes. 2017;11(2):119-131.

18. Yang W, Lu J, Weng J, Jia W, Ji L, Xiao J, Shan Z, Liu J, Tian H, Ji Q, Zhu D, Ge J, Lin L, Chen L, Guo X, Zhao Z, Li Q, Zhou Z, Shan G, He J; China National Diabetes and Metabolic Disorders Study Groups. Prevalence of diabetes among men and women in China. N Engl J Med. 2010;362(12):1090-101.

19. Huang XB, Tang WW, Liu Y, Hu R, Ouyang LY, Liu JX, Li XJ, Yi YJ, Wang TD, Zhao SP. Prevalence of diabetes and unrecognized diabetes in hypertensive patients aged 40 to 79 years in southwest China.PLoSOne. 2017;12(2):e0170250.

20-Echouffo-Tcheugui JB, Mayige M, Ogbera AO, Sobngwi E, Kengne AP. Screening for hyperglycemia in the developing world: rationale, challenges and opportunities. Diabetes Res Clin Pract. 2012;98(2):199-208.

21. Gu P, Jiang W, Cheng M, Lu B, Shao J, Du H, Jiang S.Glucose metabolism in outpatients with new-onset hypertension in Chinese Han population. Clin Exp Hypertens. 2012;34(7):47481.

22. Barrett-Connor E, Ferrara A. Isolated postchallenge hyperglycemia and the risk of fatalcardiovasculardisease in olderwomenand men. TheRanchoBernardoStudy. DiabetesCare. 1998;21(8):1236-9. 
